\title{
Pesquisa disciplinar do corpus documental das teses de doutorado do PPGCI-IBICT/UFRJ: aplicando princípios e categorias para estudo interdisciplinar da ciência da informação no Brasil
}

Ercilia Mendonça

Mestre em ciência da informação.

E-mail: ercilia.mendonca@uol.com.br

\begin{abstract}
Resumo
A partir do histórico da ciência da informação no Brasil, realizouse estudo visando a investigar, mediante princípios e categorias, a relação das disciplinas com a ciência da informação. 0 modelo aplicado dividiu o corpus de 58 teses em três categorias: disciplinas como conjuntos distintos, já que os conceitos e métodos dessa categoria não são suficientes para formalizar um quadro interdisciplinar. A segunda pela interação dos conceitos abordados, com encadeamento das questões colocadas pelas disciplinas na busca de solução para o problema proposto. A terceira remete à integração entre a disciplina e a ciência da informação, apresentando uma linguagem comum. O resultado do estudo visa a contribuir para a criação de um método de pesquisa interdisciplinar para a pós-graduação brasileira.
\end{abstract}

\section{Palavras-chave}

Ciência da Informação. Disciplina. Teses. Interdisciplinaridade.

Discipline research of the documental corpus from doctoral thesis in the Information Science Post-Graduation Program (PPGCI/IBICT/UFRJ): working on principles and categories for an interdisciplinary study of information science in Brazil

\footnotetext{
Abstract

Based on the background of Information Science in Brazil, during ten years, from 1994 to 2005, of doctorate of the PostGraduation Program in Information Science according to agreement signed between CNPq/IBICT and UFRJ/ECO, 58 theses were published. The objective of this study is to investigate, through principles and categories, the relation of the different disciplines to information science. The model used divided the corpus of theses into three categories: the first refers to the fact that the disciplies are distinct sets, each one remaining at the surface of the approach, because the concepts and methods of category were not entirely fit for formalizing an interdisciplinary frame. The second category refers to the interaction of the concepts approached with a link of the issues placed by the disciplines seeking solution for the proposed problem. The third category refers to the integration between the discipline and information science, presenting a common language. The conclusion is that the results of this study will be a contribution for the establishment of a method of interdisciplinary research for Brazilian post-graduation.
}

Keywords

Information Science. Disciplines. Thesis. Interdisciplinarity.

\author{
INTRODUÇÃO
}

Surgido a partir da experiência bem-sucedida dos cursos de especialização, especialmente o CDC, o mestrado em ciência da informação, criado por Célia Ribeiro Zaher, teve início em junho de 1972. Vinte anos depois, em 1992, teve início o doutorado em ciência da informação, que se constituiu de uma linha de pesquisa específica dentro do doutorado em comunicação da Escola de Comunicação da Universidade Federal do Rio de Janeiro, o que proporcionou sua implementação de forma independente. Em 27 de novembro de 2000, a ECO/ UFRJ comunicou a não renovação do convênio com o Instituto Brasileiro de Informação em Ciência e Tecnologia, e em 2003 teve início a parceria Ibict Universidade Federal Fluminense (UFF).

Esta síntese temporal fecha um ciclo de produção de conhecimento da ciência da informação no Brasil, que após 36 anos de mestrado e dez de doutorado leva a Capes a reconhecer que a ciência da informação entrou em uma nova fase e que espera que este arcabouço teórico formado pelas teses de doutorado seja revertido para a graduação em ciência da informação, que de forma desordenada e talvez imprópria na sua concepção propagou-se pelas universidades brasileiras.

Espera-se que o conhecimento contido nas teses sirva de referência para planejar melhor os estudos de ciência da informação no país. Esta expectativa apenas terá resultado com estudos sobre o que foi produzido neste período fértil de criação na ciência da informação.

Esta é a proposta deste trabalho, que visando a modelos conceituais de identificação e de avaliação interdisciplinar realizou análise de conteúdo na produção de conhecimento dos dez anos de doutorado do Programa de Pós-Graduação em Ciência da Informação do convênio CNPq/IBICT - UFRJ/ECO, que vigorou de 1994 a 2005 produzindo 58 teses, das quais 57 foram pesquisadas. 
Pesquisa disciplinar do corpus documental das teses de doutorado do PPGCI-IBICT/UFRJ: aplicando princípios e categorias para estudo interdisciplinar da ciência da informação no Brasil

\section{METODOLOGIA}

A tese como fonte de pesquisa constitui-se num corpus de documento. Franco (2005, p. 49), citando Bardin, diz que corpus "é o conjunto de documentos tidos em conta para serem submetidos aos procedimentos analíticos". Tendo como base esta definição, trabalhamos o corpus das teses do ponto de vista da análise de conteúdo, o que permitiu, a partir de leitura crítica, identificar características do texto para fazer inferências.

Franco (2005, p. 25) observa que uma das principais finalidades da análise de conteúdo é a produção de inferência, que neste trabalho atende ao propósito de visitar o conteúdo das teses e inferi-lo com base no escopo (alvo, finalidade, propósito), nos postulados (proposições para proceder a um raciocínio) e no arcabouço (esboço, armação, construção, estrutura) da ciência da informação.

$\mathrm{Na}$ aplicação da análise de conteúdo, Franco (2005, p. 26) aponta três fases: a descrição, a interpretação e a inferência. A descrição se relaciona com as características do conteúdo a ser analisado. Nesta buscamos observar nas teses as características inerentes à ciência da informação, ou seja, aspectos da área em que estava sendo realizado o doutorado. A interpretação se relaciona com o significado, no qual procuramos relatar o apreendido. A inferência é a fase que permite a passagem da descrição à interpretação conferindo relevância teórica à análise de conteúdo. Ao articular a descrição e interpretação dos dados, buscamos nas teses os fundamentos da ciência da informação.

A escolha de um corpus de documentos para análise implica seleção e regras, das quais Franco (2005, p. 51) aponta três regras principais: a regra da exaustividade, em que é necessário considerar todos os elementos desse corpus; a regra da representatividade, em que a análise efetua-se por amostragem, recurso utilizado para material demasiadamente volumoso; a regra da homogeneidade, em que os documentos devem obedecer a critérios precisos de escolhas e não apresentar singularidade que extrapole os critérios e os objetivos definidos.

A regra adotada foi a da exaustividade, uma vez que consideramos como campo de análise todo o corpus das teses, todos os elementos que o constituem. As regras de homogeneidade e de representatividade não se aplicaram ao estudo das teses pelo fato de se tratar de documento singular e por não caber o recurso de amostragem, dado que consideramos como relevante o período de construção do corpus.
A partir daí, empreendemos estudo no conteúdo do corpus, buscando identificar a integração, a reciprocidade, a comunicação de idéias e o intercâmbio entre a disciplina e a ciência da informação, cujo aporte constituiu-se a meta de estudo desse corpus, tendo como vínculo a comparação e o confronto da abordagem.

Para tanto, elaboramos um conjunto de cinco princípios que visam a investigar o estudo interdisciplinar entre a disciplina e a ciência da informação, ou seja, a relação desses conhecimentos.

Estes princípios formam um conjunto de cinco recomendações técnicas:

1) observar o modo com que o pesquisador se refere ao objeto de sua disciplina no contexto da ciência da informação, tentando identificar qualquer definição que apresente intenção interativa;

2) verificar o tratamento que o pesquisador dá ao objeto no processo de comunicação entre a disciplina e a ciência da informação;

3) atentar para o fato de como a pesquisa busca integrar informação em ciência da informação com o objeto de estudo da disciplina;

4) observar o trabalho de conceituação de informação como meio para viabilizar o objeto de estudo na área de conhecimento da disciplina e da ciência da informação, simultaneamente;

5) verificar se houve relação, integração de conceitos diferentes e pertinentes à compreensão de estudo do objeto da disciplina.

Tendo os princípios como referência de análise, embasamos nossa pesquisa com os conceitos de disciplina científica de Japiassu (1976) e os conceitos de interdisciplinaridade científica de Lenoir (2005).

Japiassu (1976, p. 60) destaca sete fundamentos que determinam o corpo de uma disciplina científica: o domínio material, que são os objetos pelos quais se ocupam; o domínio de estudo, que é o ângulo específico em que considera seu objeto de estudo; o nível de integração teórica, que são os conceitos fundamentais e unificadores que abrangem os fenômenos próprios do domínio de estudo; os métodos, que são os instrumentos pelos quais a disciplina apreende e transforma os fenômenos, com concordância entre a aplicação do 
método e as leis para integração teórica; os instrumentos de análise, que são as estratégias, os raciocínios e a construção de modelos; as aplicações, que se referem às orientações dirigidas, no caso de aplicação profissional, revela opção epistemológica; e por fim, as contingências históricas, que são as fases, momentos transitórios de cada disciplina.

Lenoir (2005, p. 52) destaca os fundamentos da interdisciplinaridade científica: Finalidades são a produção de novos conhecimentos e a resposta às necessidades sociais pelo estabelecimento de ligações entre ramificações da ciência pela hierarquização, pela estrutura epistemológica e pela compreensão de diferentes perspectivas disciplinares, restabelecendo as conexões sobre o plano comunicacional entre os discursos disciplinares. Objetos são os que têm por objetivo as disciplinas científicas. Modalidades de Aplicação são as que implicam a noção de pesquisa que tem o conhecimento como sistema de referência. Sistema Referencial é o retorno à disciplina na qualidade de ciência. Conseqüência é o que conduz à produção de novas disciplinas segundo diversos processos e às realizações técnico-científicas. Estas características pressupõem a existência de duas disciplinas para uma ação recíproca com o esforço de aproximar, comparar, relacionar e integrar conhecimentos.

Este quadro de identificação e análise teve como propósito criar as categorias de classificação do interdisciplinar: paralelismo, interdependência e interseção para aplicálas ao corpus documental das teses no intuito de contribuir com um método de estudo interdisciplinar não só para a ciência da informação, mas para a pósgraduação no Brasil.

A proposta deste trabalho foi demonstrar a necessidade de instituir critérios práticos, teóricos e conceituais de avaliação visando a identificar o interdisciplinar na área de produção de conhecimento, com vistas à mensuração da relação entre a disciplina que busca dialogar com a ciência da informação. Buscamos, assim, formalizar um campo específico de estudo entre as disciplinas, a ciência da informação e as áreas de conhecimento.

O CAMPO DE ESTUDO DISCIPLINAR E A CONSTRUÇÃO DE CONHECIMENTO DA CIÊNCIA DA INFORMAÇÃO NO BRASIL

No contexto histórico de sua evolução, a primeira disciplina que formalizou uma problemática informacional na pesquisa do curso de doutorado em ciência da informação foi a física, em 1994. A segunda foi a biblioteconomia, em 1997. Em 1998, foram seis: análise de sistema; engenharia química; economia; arquitetura e urbanismo; história e letras. Em 1999, a geografia. Em 2000, a biologia e a museologia. Em 2001, buscaram auxílio a comunicação visual, a sociologia e a arqueologia. Em 2002, apenas a comunicação social, e em 2003, a medicina. Em 2004, artes plásticas. Em 2005, farmácia e bioquímica bem como arquivologia, que fecharam o ciclo de estudos disciplinares com a ciência da informação nas áreas de ciências sociais aplicadas; ciências humanas; engenharias; ciências biológicas; ciências da saúde; lingüística, letras e artes; ciências exatas e da terra. Este é o quadro de relação das disciplinas com a ciência da informação.

Pode-se afirmar que o caráter interdisciplinar da ciência da informação está na sua capacidade de incorporar e tomar por empréstimo esquemas conceituais, o que lhe dá legitimidade, como pode ser verificado em Japiassu (1976), Teixeira (2004) e Gomes (2001), autores utilizados para embasar esta parte.

Para Japiassu (1976, p. 74), a interdisciplinaridade se diferencia pela intensidade das trocas entre os especialistas, pelo grau de integração disciplinar, conceitual e metodológica. $\mathrm{O}$ interdisciplinar se destaca por estar além de um simples monólogo, ou de um diálogo paralelo, pois a interdisciplinaridade visa a união do conhecimento. O autor considera que o papel do interdisciplinar

consiste, primordialmente, em lançar uma ponte para religar as fronteiras que haviam sido estabelecidas anteriormente entre disciplinas com o objetivo preciso de assegurar a cada uma seu caráter propriamente positivo, segundo modos particulares e com resultados específicos (1976, p. 75).

Japiassu (1976, p. 52) declara: "o que importa é constatar todo um esforço de aproximar, comparar, relacionar e integrar os conhecimentos”, destacando que

o interesse crescente pelo problema da interdisciplinaridade manifesta-se em nossos dias em numerosos trabalhos tendo por preocupação fundamental o confronto dos especialistas de diversas disciplinas para que seja desencadeado um processo de reorganização do saber, com vistas, na prática, a um planejamento dos recursos humanos. 
Pesquisa disciplinar do corpus documental das teses de doutorado do PPGCI-IBICT/UFRJ: aplicando princípios e categorias para estudo interdisciplinar da ciência da informação no Brasil

Para Teixeira (2004, p. 62-63), as práticas interdisciplinares colocam problemas e desafios que precisam ser enfrentados, alertando para o fato de que é necessário construir objetos científicos interdisciplinares, e que este caminho

é a valorização das controvérsias disciplinares no intuito de construir uma problemática comum e progressiva. De modo geral, toda problemática interdisciplinar deve emergir da confrontação disciplinar, o que modifica - obrigatoriamente - a visão particular de cada um sobre as questões levantadas, os conceitos utilizados, os métodos e instrumentos definidos, a estratégias de amostragem.

Teixeira argumenta (2004, p. 64) que

a problemática comum é progressiva e deve ser entendida como o fio condutor da interdisciplinaridade. Isto é, a problemática comum deve ser percebida como um conjunto articulado de questões formuladas pelas deferentes disciplinas envolvendo um tema e um objeto comum.

Reafirmando a questão proposta neste trabalho, citamos ainda Teixeira (2004, p. 57), que sinaliza três problemáticas do marco teórico da interdisciplinaridade na pesquisa e na pós-graduação brasileira:

- a importância de uma metodologia interdisciplinar;

- a formação coletiva de pesquisadores;

- a síntese, análise dos trabalhos.

A primeira encontra ressonância na proposta desta pesquisa, que busca desenvolver método de análise e avaliação para o estudo interdisciplinar da ciência da informação. A última problemática, segundo o autor, demonstra o caráter fundamental de organização científica da pesquisa interdisciplinar, pois ela é mais um ponto de partida que de chegada, não sendo dada antecipadamente por regras, fórmulas ou modelos (TEIXEIRA, p. 64).

Gomes (2001, p. 3), ao examinar a questão disciplinar no âmbito da ciência da informação com vista à interdisciplinaridade, assegura que

uma ciência pressupõe um núcleo de conhecimentos, métodos de investigação e um campo experimental para que se possam criar os contextos de interação que pressupõem a troca de conhecimentos e de métodos com outras disciplinas.
A autora (2001, p. 01) argumenta que

qualquer discussão que pretenda abordar a problemática da interdisciplinaridade na Ciência da Informação vindica que, mesmo de forma ligeira, se reflita sobre o significado de disciplina e sua relação com a construção do conhecimento científico, que a caracteriza enquanto objeto de ensino e de aprendizagem.

Esta reflexão, segundo Gomes (2001, p. 4), é fundamental, não para confirmar a característica interdisciplinar da Ciência da Informação, porque seu objeto de estudo aponta para a relevância deste seu caráter mas, para que se possa verificar quais as disciplinas que de fato dialogam com ela a ponto de atualizarem esta interdisciplinaridade, justificando a inclusão dessas disciplinas na composição do núcleo principal da Ciência da Informação.

Gomes (2001, p. 4) relata que este procedimento visa a expandir suas zonas teóricas, sua inserção em cada disciplina, identificando suas contribuições. Neste sentido, a autora declara que

seria de fundamental importância que a ciência da informação realizasse uma análise rigorosa sobre como seu arcabouço teórico é colocado em atividade objetiva a partir das áreas com as quais tem buscado dialogar.

Estas citações reforçam a importância, a partir dos estudos realizados, de criar modelos de análise e de avaliação visando à perspectiva interdisciplinar brasileira. A identificação e mapeamento das relações disciplinares fornecerão instrumentos teórico-conceituais e práticos ao fazer interdisciplinar.

É de fundamental importância:

- fortalecer a aplicação das teorias, leis e métodos do arcabouço da ciência da informação;

- identificar a(s) teoria(s) compatíveis, ideais, próprias ao campo de estudo da ciência da informação;

- estimular a pesquisa teórico-conceitual e a construção de novos conhecimentos baseados nos postulados da ciência da informação;

- fortalecer a ação da informação como sustentáculo desta ciência e como conceito que a priori identifica o objeto de qualquer disciplina; 
- conhecer o processo em que se dá a troca para possíveis cooperações;

- sensibilizar os pesquisadores para a necessidade de uso do aporte teórico da ciência da informação como forma de estabelecer e legitimar, na prática, seu conteúdo interdisciplinar.

Com base nestes mecanismos de pesquisa e visando ao efetivo uso do aporte da ciência da informação, realizamos nas partes pré-textuais das teses uma busca pelo termo "ciência da informação".

Segundo a Associação Brasileira de Normas Técnicas (ABNT), a estrutura das partes pré-textuais de um trabalho técnico ou científico deve refletir a área da pesquisa, o assunto tratado, os pontos relevantes e a visão de conjunto, o que favorece o tratamento desse documento no processamento da informação (classificação, catalogação e indexação), facilitando sua localização num corpo de conhecimento.

A ciência da informação como área de estudos de informação é cientificamente necessária no processo de produção de conhecimento em um programa de pesquisa assim denominado. Partindo dessa premissa, adotamos o título, o resumo e o sumário das teses, empreendendo busca do termo 'ciência da informação' com o propósito de identificar a área de conhecimento em que as pesquisas das teses foram realizadas.

A seguir, o gráfico representativo do levantamento cujo objetivo não foi medir a interdisciplinaridade da área, mas revelar a importância de uso do arcabouço da ciência da informação nos estudos disciplinares.

A freqüência do termo 'ciência da informação' nas partes pré-textuais - título, resumo e sumário das 57 teses estudadas - apontou que 28 , ou seja, $49,12 \%$ não trazem o termo que denomina a área de estudo do programa de pós-graduação; 13 teses ou 22,81\% apresentaram o termo no resumo e no sumário; sete ou $12,28 \%$ apenas no sumário; cinco ou 8,77\% no título, resumo e sumário; duas ou $3,51 \%$ apenas no resumo; uma ou $1,75 \%$ no título; uma tese ou $1,75 \%$ no título e resumo.
GRÁFICO 1

Freqüência do termo "ciência da informação" nas partes pré-textuais das teses

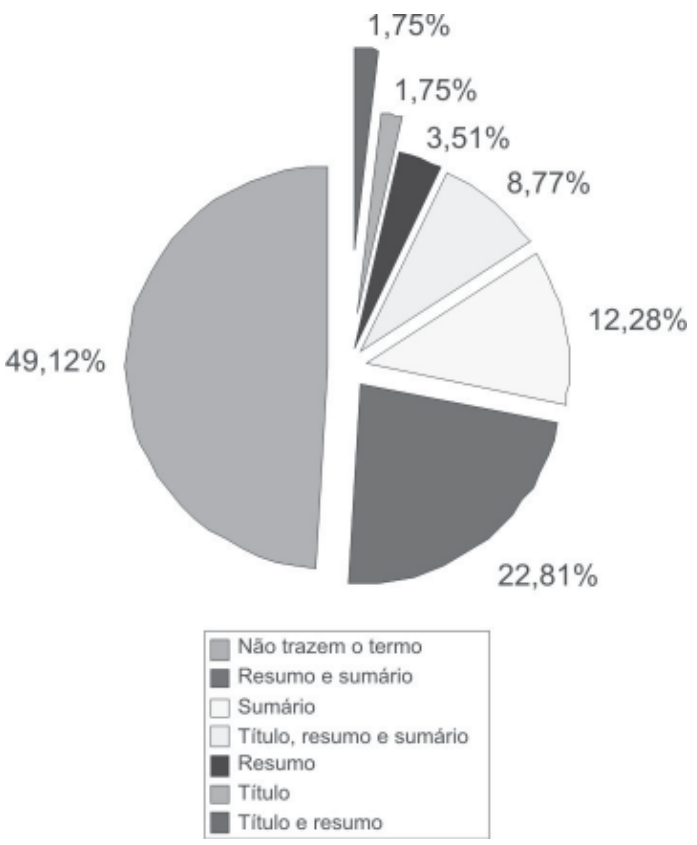

\section{APLICANDO AS CATEGORIAS DE ESTUDOS INTERDISCIPLINARES PARA A CIÊNCIA DA INFORMAÇÃO BRASILEIRA}

Como disciplina, a ciência da informação está localizada na área de ciências sociais aplicadas, junto com biblioteconomia, museologia, comunicação social, economia, arquitetura e urbanismo, arquivologia, comunicação visual e análise de sistema. História, sociologia e arqueologia nas ciências humanas, letras e artes plásticas na lingüística, letras e artes, física e geografia nas ciências exatas e da terra, biologia, farmácia e bioquímica nas ciências biológicas; medicina nas ciências da saúde; engenharia química e engenharia naval nas engenharias.

Estas foram as sete grandes áreas e as 20 disciplinas que buscaram resolução de problema na ciência da informação nos dez anos de produção de conhecimento, que necessitam ser investigadas para legitimar o discurso interdisciplinar da pós-graduação no Brasil.

Tendo em vista a questão das relações disciplinares com a ciência da informação, destacamos as designações conceituais de disciplina dadas por Lenoir apud Amaral (1997), que informa: 
- disciplina produz instrumentos intelectuais e teorias para desenvolver capacidades e habilidades específicas para manipular ferramentas;

- disciplina oferece operadores práticos voltados para organização;

- disciplina representa um corpus de estrutura organizada de interesse para o pesquisador que pretende conduzir suas pesquisas em área que conhece e domina, por ser sua área de formação;

- disciplina fornece suporte para modelos discursivos de práticas e estruturas de conhecimento;

- disciplina possibilita sistematização, organização e incorporação de práticas adquiridas com outras disciplinas;

- é por meio da disciplina que se reúnem, direcionam e reproduzem as políticas técnicas e sociais.

Essas designações reforçam a idéia das categorias de análise: modos de colaboração e relações interdisciplinares que visam a sintetizar e sistematizar o estudo disciplinar na ciência da informação.

A finalidade das categorias foi submeter o conteúdo das teses para verificar a interação, a integração e a interseção da disciplina com a ciência da informação como área de estudos de informação. O reconhecimento do papel desses modos e relações é de fundamental importância nos estudos da ciência da informação, pois está relacionado com sua existência como ciência interdisciplinar.

A seguir, as categorias de análise, o quadro com a distribuição das teses e a descrição conceitual das categorias aplicadas ao corpus das teses.

\section{Modos de colaboração}

Paralelismo - Ausência de colaboração dos conceitos buscados para trabalhar o objeto de pesquisa. As disciplinas constituem conjuntos distintos, permanecendo cada uma na superfície da abordagem. Não colaboração.

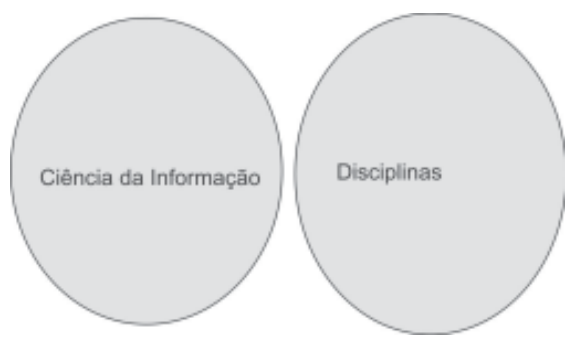

Ci. Inf., Brasília, v. 37, n. 2, p. 58-69, maio/ago. 2008
Interdependência - Interação entre conteúdo e abordagem. Há encadeamento das questões colocadas pelas disciplinas na busca de solução para o problema proposto. A interdependência requer freqüência no confronto das questões, modificando/enriquecendo cada disciplina no seu contexto. Semicolaboração.

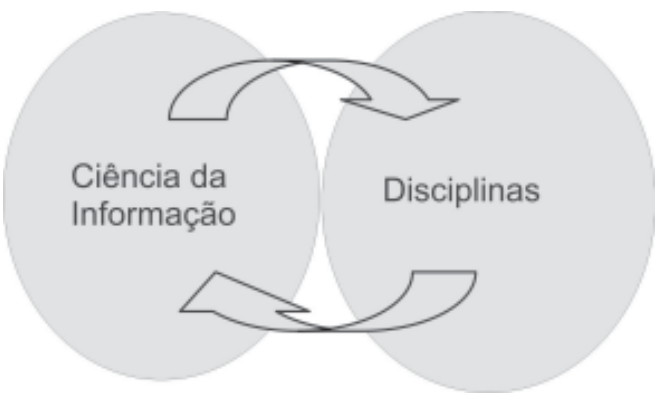

Interseção - Integração do diálogo buscado, permuta recíproca. Linguagem comum particularizada com diálogo fértil facilitada pelo contexto e conceito do saber que integra as disciplinas. Do ponto de vista interdisciplinar, houve integração de conceitos. Colaboração efetiva.

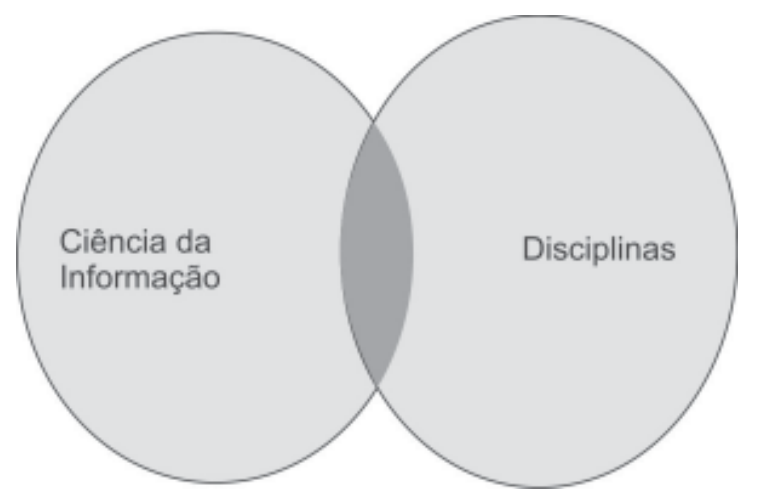

Relações interdisciplinares

Interdisciplinaridade linear - Esta nomeação se justifica pelo uso de conceitos e análises que não são suficientes para formalizar a concepção interdisciplinar. Após o estudo, percebe-se a não concretização do proposto, ou seja, a não integração do domínio de estudo e da teoria utilizada. Ex: ciência da informação + cultura; ciência da informação + tecnologia.

Interdisciplinaridade auxiliar - Esta nomeação se dá pelo empréstimo de métodos e procedimentos em que são fornecidas informações para o domínio de estudo da disciplina. Esta relação prevê dois tipos de situação: 
ocasional e semipermanente, uma vez que a disciplina necessita de apoio constante para resolução de suas práticas informacionais que demandam níveis diversos na área de atuação. Ex: ciência da informação + medicina.

Interdisciplinaridade unificada - Esta relação se dá pela coerência dos domínios das disciplinas, em que há integração de teorias, métodos e problemas. As disciplinas se comunicam dentro do mesmo diálogo, havendo enriquecimento mútuo que é fundamental para a fecundação recíproca das disciplinas. Ex: ciência da informação + lingüística; ciência da informação + biblioteconomia.
Os modos de colaboração funcionam como objetivo geral entre a disciplina e a ciência da informação e dão a perspectiva de entrosamento. As relações interdisciplinares são consideradas como objetivos específicos, pois explicam e aprofundam essa perspectiva indicando caminhos de domínio entre a disciplina e a ciência da informação.

quadro $\mathrm{n}^{\circ} 1$ com a distribuição das teses representa um método de investigação que levou em consideração a troca de conhecimento entre a disciplina e a ciência da informação, dado que, segundo Japiassu (1976, p. 124),

a reflexão crítica [sobre as pesquisas realizadas] funda a pesquisa interdisciplinar na medida em que é capaz de desvelar seu sentido e de justificá-la racionalmente.

QUADRO 1

Distribuição das teses pelas categorias

\begin{tabular}{|c|c|c|c|c|c|}
\hline \multicolumn{3}{|c|}{ Modalidades de colaboração } & \multirow{4}{*}{ Disciplinas } & \multirow{4}{*}{ Qtd } & \multirow{4}{*}{ Grande área } \\
\hline Paralelismo & Interdependência & Interseção & & & \\
\hline \multicolumn{3}{|c|}{ Relações interdisciplinares } & & & \\
\hline Linear & Auxiliar & Unificada & & & \\
\hline $4,35,51$ & $2,14,25,40,42,44$ & $15,21,45,52$ & Biblioteconomia & 13 & \multirow{8}{*}{$\operatorname{CSA}$} \\
\hline 23 & $13,29,31,34,50$ & . & Museologia & 6 & \\
\hline 49 & $22,33,46$ & 30,39 & Comunicação Social & 6 & \\
\hline $5,11,27$ & 38 & $\cdot$ & Economia & 4 & \\
\hline . & $3,47,58$ & . & Arquitetura e Urbanismo & 3 & \\
\hline 57 & . & . & Arquivologia & 1 & \\
\hline . & 19 & . & Comunicaçāo Visual & 1 & \\
\hline . & 9 & . & Análise de Sistema & 1 & \\
\hline . & $6,24,41$ & 54,56 & História & 5 & \multirow{3}{*}{$\mathrm{CH}$} \\
\hline . & 17 & $\cdot$ & Arqueologia & 1 & \\
\hline . & . & 18 & Sociologia & 1 & \\
\hline . & 16,36 & $7,20,26$ & Letras & 5 & \multirow[t]{2}{*}{ LLA } \\
\hline 37 & 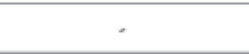 & 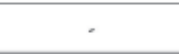 & Artes Plásticas & 1 & \\
\hline . & . & 12 & Biologia & 1 & \multirow{2}{*}{$\mathrm{CB}$} \\
\hline 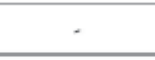 & 48 & $\cdot$ & Farmácia e bioquimica & 1 & \\
\hline 55 & 28,43 & - & Medicina & 3 & $\mathrm{CS}$ \\
\hline . & 1 & . & Fisica & 1 & \multirow[t]{2}{*}{ CET } \\
\hline . & - & 10 & Geografia & 1 & \\
\hline 8 & . & . & Engenharia Quimica & 1 & \multirow[t]{2}{*}{ Engenharias } \\
\hline 53 & . & . & Engenharia Naval & 1 & \\
\hline 13 & 30 & 14 & 20 & $57^{*}$ & 7 \\
\hline
\end{tabular}

* O estudo foi realizado em 57 teses porque a tese de n 32 , apesar dos esforços empreendidos, não foi localizada. 
Pesquisa disciplinar do corpus documental das teses de doutorado do PPGCI-IBICT/UFRJ: aplicando princípios e categorias para estudo interdisciplinar da ciência da informação no Brasil

\section{DESCRIÇÃO CONCEITUAL DAS CATEGORIAS APLICADAS AO CORPUS DOCUMENTAL DAS TESES}

\section{Paralelismo}

A pesquisa classificou nesta categoria 13 teses que estão distribuídas pelas disciplinas biblioteconomia ( ${ }^{\circ} \mathrm{s} 4,35$, 51); economia ( $\left.\mathrm{n}^{\circ} \mathrm{s} 5,11,27\right)$; museologia ( $\left.\mathrm{n}^{\circ} 23\right)$; comunicação social ( $\left.{ }^{\circ} 49\right)$; arquivologia ( $\left.{ }^{\circ} 57\right)$; artes plásticas ( $\left.n^{\circ} 37\right)$; medicina ( $\left.{ }^{\circ} 55\right)$; engenharia química ( $\mathrm{n}^{\circ} 8$ ); engenharia naval ( $\mathrm{n}^{\circ} 53$ ). Destes 13 autores, 7 representados pelas teses $n^{\circ}$ s $4,35,51 ; 8 ; 23 ; 37 ; 55$ fizeram mestrado em ciência da informação.

Esta categoria traz o fato de as disciplinas constituírem conjuntos distintos, permanecendo cada uma na superfície da abordagem sem integração, reciprocidade, intercâmbio com a área em que está sendo realizado o estudo.

A pesquisa verificou que, pela análise de conteúdo, as teses desta categoria não apresentaram interação do objeto estudado com a ciência da informação. Faltaram comunicação de idéias, intercâmbio mútuo e integração recíproca entre conceitos.

Com base na leitura realizada, a informação referida não apresentou intenção interativa ao relacionar conceitos diferentes e pertinentes necessários à compreensão de estudo do objeto da disciplina com a ciência da informação.

A pesquisa identificou que um fato comum às teses desta categoria é a presença do termo informação, o quê, por si só, não representa interação, integração, reciprocidade, intercâmbio com a ciência da informação, pois segundo Barreto (2005, p. 2),

não se pode, simplesmente, transpor teorias e conceitos emprestados de outra área de conhecimento. Esta transmutação de idéias, do pensar em si tem que respeitar as características existentes e manifestas da área de ciência da informação, do objeto informação em si, com todas as suas condições, características e singularidades.

No que concerne à relação da disciplina com a ciência da informação, a pesquisa demonstrou que a economia teve quatro representes nos dez anos e que três deles encontram-se nesta categoria, as teses $n^{\circ} \mathrm{S} 5,11$ e 27 , o que demonstra a necessidade de realizar maiores estudos para investigar questões relevantes da disciplina economia no conjunto de leis, métodos e aplicações da ciência da informação.

Os estudos apresentados adotaram a abordagem de políticas públicas e gestão sem um domínio específico que configure um campo de pesquisa científica e técnica de informação no âmbito econômico.

As teses $n^{\circ} \mathrm{S} 5$ e 11 tiveram como objeto de pesquisa a estatística, visando a ação de políticas públicas. Este objeto não alcançou apropriação do conceito de informação com a ciência da informação pela ausência de entrosamento dos conceitos utilizados.

A tese $n^{\circ} 27$ buscou a compreensão da gestão urbana informacional, mas os conceitos trabalhados ao longo da tese não alcançaram intenção interativa que permitisse identificação do objeto presente no corpo da área de estudo da tese.

Quanto à medicina, a única tese classificada nesta categoria foi a de $n^{\circ} 55$, que apesar da freqüente presença do termo informação e do contexto informacional, não logrou integração com a área em que estava sendo desenvolvida a pesquisa. A informação ali registrada não alcançou representação conceitual no âmbito dos estudos de informação no contexto da ciência da informação.

A biblioteconomia teve três teses nesta categoria, duas (n ${ }^{\circ}$ s 4 e 51) com a temática comunicação científica e uma (no 35) com a temática da gestão do conhecimento.

A tese de $\mathrm{n}^{\circ} 4$ desenvolve a pesquisa sob o foco da ciência, tendo como interface a sociologia da ciência; no entanto, não interage o conceito utilizado para trabalhar o objeto da pesquisa com o arcabouço da ciência da informação.

A tese de $n^{\circ} 35$, primeira representante a inserir o tema gestão do conhecimento como objeto de pesquisa no doutorado em ciência da informação, apresentou seu objeto sob o olhar da cultura organizacional e o comportamento dos indivíduos desenvolvendo a pesquisa a partir da ótica de autores e conceitos da gestão do conhecimento sem interagir com o campo em que estava sendo realizado o estudo.

A pesquisa verificou que estes temas - comunicação científica e gestão do conhecimento, relevantes para o escopo da ciência da informação - necessitam de mais pesquisas no nível de doutorado para tornar-se parte específica de um grupo de estudo, tendo em vista a amplitude e complexidade desses assuntos. 
A comunicação científica, com a implantação das redes iniciada na década de 90 , requer estudos sistemáticos no âmbito da ciência da informação. A gestão do conhecimento, que visa a estratégia organizacional, administração e negócios, representa o estudo da capacidade de agir diante de uma informação, o que a difere de gestão da informação, que são os dados organizados em uma estrutura. A gestão do conhecimento traz um desafio para a ciência da informação: como trabalhar a complexidade desse tema, organizá-lo e ao mesmo tempo se auto-organizar?

Tanto a comunicação científica quanto a gestão do conhecimento carecem de pesquisas para formalizar um grupo de estudo com autores, conceitos e linguagem própria nos estudos de informação.

É importante destacar que os estudos de comunicação científica no âmbito da ciência da informação, segundo reformulações curriculares ocorridas no período de 1998 e 2000, estão representados pela área de concentração de $n^{\circ} 1$ - Conhecimento, Processos de Comunicação e Informação, na linha de pesquisa 1.2 - Processamento e Tecnologia de Informação.

Já a gestão do conhecimento encontra-se na área de concentração de no 2 - Política e Gestão do Conhecimento e da Informação, dividida nas linhas de pesquisa 2.1 - Configurações Sociais e Políticas da Informação e 2.2 - Gestão da Informação. Não há linha de pesquisa específica para gestão do conhecimento. A linha de pesquisa 2.2 está voltada para a gestão da informação, implantada em 1998 e que até o término do convênio apresentou apenas uma tese, a de $n^{\circ} 53$, concluída em 2005.

Quanto às engenharias, a pesquisa classificou nesta categoria as duas únicas teses ( ${ }^{\circ} \mathrm{s} 8$ e 53 ), por apresentarem paralelismo com a ciência da informação.

$\mathrm{Na}$ engenharia química, tese $\mathrm{n}^{\circ} 8$, a autora desenvolveu um estudo de caso no setor industrial de petróleo e gás no Mar do Norte da Grã-Bretanha, com vistas às trocas dessa comunidade. O tema, focado nas inovações tecnológicas utilizadas pela indústria, não demonstrou intenção interativa com a ciência da informação.

A engenharia naval, tese de $n^{\circ} 53$, diferencia-se neste estudo pois o tema desenvolvido não tem relação direta com a formação da autora. Voltada para a questão administrativa, a tese discute a fluência em tecnologia da informação sob os procedimentos da graduação em administração, trazendo os campos de atuação, competências e habilidades desse profissional. Importante para a área de administração; no entanto, não apresentou integração no conjunto do tema em relação à área em que foi realizado o estudo.

Em relação à disciplina administração houve contribuição temática, pois a autora inseriu, no âmbito do doutorado, o conceito de "fluência" como definição para a habilidade do indivíduo a quem é permitido saber reformular e expressar conhecimento por meio tecnológico, o que o torna socialmente responsável pelo uso dessa informação. Apesar da contribuição, a pesquisa concluiu que não houve interação dos conceitos de fluência no âmbito da ciência da informação.

Dentro do mesmo padrão de análise, as teses de $n^{\circ} 23$, 37, 49 e 57, respectivamente, museologia, artes plásticas, comunicação social e arquivologia, não interagiram com a área em estudo.

Quanto às temáticas desta categoria, são bastante diversificadas, envolvendo tecnologia, produção, organização, gestão, disseminação, transferência e comunicação.

Em relação ao termo 'ciência da informação' no título, resumo e sumário, a tese de no 53 a cita uma só vez, no sumário. As outras 12 teses não indicam o termo em nenhum desses locais, ou seja, não se referem ao campo de estudo em que está sendo realizada a pesquisa da tese, o que legitima o resultado de classificação das teses nesta categoria.

\section{Interdependência}

A pesquisa classificou nesta categoria o maior número de teses, no total 30, representadas pelas seguintes disciplinas: biblioteconomia com 6 teses $\left(n^{\circ}\right.$ s 2, 14, 25, 40, 42, 44); museologia, 5 teses ( $\mathrm{n}^{\circ} \mathrm{s} 13,29,31,34,50$ ); comunicação social, 3 teses ( $n^{\circ}$ s 22, 33, 46); economia, uma tese ( $\left.n^{\circ} 38\right)$; arquitetura e urbanismo, duas teses ( $\left.{ }^{\circ}{ }^{\circ} 47,58\right)$; comunicação visual, uma tese (no 19); análise de sistema, uma tese ( $\left.n^{\circ} 9\right)$; arqueologia, uma tese ( $n^{\circ}$ 17); história, 3 teses $\left(n^{\circ} \mathrm{s} 6,24,41\right)$; letras, 2 teses $\left(n^{\circ} \mathrm{s}\right.$ 16, 36); farmácia e bioquímica, uma tese ( $\left.n^{\circ} 48\right)$; medicina, 2 teses ( $n^{\circ} \mathrm{s} 28,43$ ); física, uma tese ( $\left.\mathrm{n}^{\circ} 1\right)$. Destes 30 autores, 9 distribuídos pelas teses $n^{\circ} 14,42$, 31, 47, 19, 9, 17, 24 e 43 não fizeram mestrado em ciência da informação. Como nota, o autor da tese de no $16 \mathrm{fez}$ mestrado em ciência da informação na Universidade Federal de Minas Gerais (UFMG). 
Pesquisa disciplinar do corpus documental das teses de doutorado do PPGCI-IBICT/UFRJ: aplicando princípios e categorias para estudo interdisciplinar da ciência da informação no Brasil

A categoria interdependência está relacionada com a interação dos conceitos abordados pelo encadeamento das questões colocadas pelas disciplinas na busca de solução para o problema proposto.

É patente a questão da interdependência como um campo de auxílio para empréstimo de métodos e procedimentos em que são fornecidas informações para o domínio de estudo da disciplina com a ciência da informação, o que enriquece a relação. A interdependência pode ser ocasional ou semipermanente, uma vez que a disciplina necessita de apoio constante para suas práticas informacionais, demandando diferentes níveis de atuação.

A pesquisa mostrou que a disciplina biblioteconomia, representada por seis teses $\left(n^{\circ} \mathrm{s} 2,14,25,40,42\right.$ e 44) encontra-se em maior número nesta categoria, e os autores buscaram compreensão visando a trabalhar e criar conceitos e práticas em suas áreas de formação. A museologia, com 5 teses ( $\mathrm{n}^{\circ} \mathrm{s} 13,29,31,34$ e 50) apresentou-se como uma disciplina que busca caminhos para viabilizar seu objeto e espaço na ciência da informação. A presença maciça dessa disciplina nesta categoria reforça esse propósito. Desses autores, apenas um, o da tese de $n^{\circ} 29$, não exerce função em museu, mas em arquivo.

As teses de comunicação social, no 22, 33 e 46 trazem para a ciência da informação proposições que remetem ao passado como forma de entender e organizar o presente, para facilitar acesso no futuro. As teses de história $n^{\circ} \mathrm{s} 6,24$ e 41 e de letras, nº 16 e 36 coadunamse na busca de conceitos e na resolução de conflitos inerentes à informação nas suas áreas de atuação.

As teses de $\mathrm{n}^{\circ} 9 ; 17 ; 19 ; 38$, respectivamente, análise de sistema, arqueologia, comunicação visual e economia buscaram trabalhar conceitos com fins de aplicação. As teses de no 28 e 43 (medicina) e de no 48 (farmácia e bioquímica), no cerne da informação em saúde, discutem formas de representação da informação, agenda de prioridades e acesso para tomada de decisão profissional, todas visando a melhorar o sistema de informação em saúde para o gestor e o usuário.

A tese de $\mathrm{n}^{\circ} 1$, física, insere a questão do valor da informação sob o ponto de vista do usuário de sistema. Das três teses de arquitetura e urbanismo (nº 3, 47 e 58), apenas a de no 58 exerce função na área, cuja problemática abordou os sistemas de informação e governança, em relação à cidade e à questão urbana.
As teses de no 3 e 47 discutem questões relacionadas à informação, ciência e tecnologia, não relacionadas à disciplina de formação.

As temáticas desta categoria são transferência, tecnologia, representação, produção, políticas e gestão da informação. Os objetos são bastante diversificados, mas observa-se forte tendência para estudos de sistemas, redes e conceitos aplicados de informação.

Quanto à freqüência do termo 'ciência da informação' no título, resumo e sumário, a pesquisa mostrou que das 30 teses, apenas 12 não o citam. As teses nºs 19, 31, 41 e 47 citam o termo no título, resumo e sumário, dado que trabalham a questão de conceito na ciência da informação e na interdisciplinaridade. As outras 14 mencionam o termo alternativamente.

\section{Interseção}

Nesta categoria foram classificadas 14 teses. As disciplinas foram biblioteconomia, com quatro teses ( $n^{\circ} \mathrm{s}$ 15, 21, 45 e 52); letras com três ( $n^{\circ}$ s 7, 20 e 26); comunicação social com duas ( $n^{\circ} \mathrm{s} 30$ e 39); história com duas (nº 54 e 56); sociologia com uma ( $\left.n^{\circ} 18\right)$; biologia com uma ( $\left.n^{\circ} 12\right)$; geografia com uma ( $\left.n^{\circ} 10\right)$. Destas, apenas cinco autores não fizeram mestrado em ciência da informação (teses de $n^{\circ}$ s 30; 12; 54; 7 e 20). Como nota, o autor da tese $n^{\circ}$ $45 \mathrm{fez}$ mestrado em ciência da informação na Universidade de Brasília.

No conjunto, as 14 teses apresentaram integração, permuta recíproca entre a disciplina e a ciência da informação. Houve mútua importação e exportação de conceitos através de linguagem comum particularizada com diálogo fértil facilitado pelo campo de saber que integra as disciplinas.

Quanto às temáticas, as 14 teses têm em comum a discussão com vistas ao entrosamento de temas voltados para entender seu objeto no arcabouço da ciência da informação, tais como conceitos de representação para ambientes virtuais; resgate da historicidade da área; linguagens de representação e recuperação; hiperdocumentos; processamento de imagens; avaliação de cientistas; conservação de acervos; movimentos sociais; práticas informacionais e informação científica como instrumento institucional e social.

Em relação à freqüência do termo "ciência da informação" no título, resumo e sumário, a pesquisa mostrou que, das 14 , apenas quatro não o citam; cinco o 
mencionam no sumário e no resumo; uma tese o cita no título, resumo e sumário; as quatro restantes, alternativamente.

Cumpre destacar ser este o primeiro estudo experimental realizado no corpus documental das teses de doutorado em ciência da informação que teve como propósito investigar a interdisciplinaridade da área no Brasil. Buscamos com esta abordagem experimental a apreensão e a compreensão do campo interdisciplinar na pósgraduação brasileira.

\section{CONSIDERAÇÕES FINAIS}

Ao concluir este estudo no corpus documental das teses de doutorado em ciência da informação, assumimos que nenhum pesquisador está isento de comprometer-se com sua pesquisa, dado que não utilizamos termos ou expressões neutras que nos coloquem fora do comprometimento com a pesquisa realizada e aqui apresentada.

A ciência da informação brasileira carece de pesquisadores comprometidos com o seu fazer. $\mathrm{O}$ ousar fazer, a crítica ou elogio provenientes dessa ação são práticas saudáveis que auxiliarão a reflexão e, conseqüentemente, a ampliação de idéias e estudos técnicos e científicos que terão como meta organizar e sistematizar a pesquisa interdisciplinar da pós-graduação brasileira.

Contextualizamos os princípios e as categorias criadas com as idéias e conceitos dos autores citados visando a uma metodologia do interdisciplinar que poderá constituir-se em modos de análise e avaliação de estudos não apenas nos domínios da ciência da informação, mas de outras áreas de conhecimento.

Tendo em vista o desenvolvimento técnico, teórico e científico da ciência da informação no Brasil, sugerimos dois pontos básicos como procedimentos que poderão definir sua base epistemológica, uma vez que a relevância de sua produção se dá por intermédio do mestrado e do doutorado ministrado nas universidades brasileiras.

Sugestão no 1 - colocar em discussão a adoção de princípios que norteiem seus estudos para formalizar o campo de investigação teórico-científico interdisciplinar da área;

sugestão $\mathrm{n}^{\circ} 2$ - em complemento aos princípios, adotar categorias de análise como meio de constituir uma linha de avaliação da produção de conhecimento da área, uma vez que a interdisciplinaridade carece de graus e modos de relação para se estabelecer.

Apenas desta forma vamos poder definir a base de investigação científica da ciência da informação no Brasil, uma vez que a pesquisa revelou uma fragilidade teórico-conceitual já constatada anteriormente em outros trabalhos, alguns aqui citados. De modo geral, a ciência da informação carece de critérios práticos, técnicos, teóricos e conceituais que identifiquem seu campo de conhecimento interdisciplinar no país.

Artigo submetido em 04/11/2008 e aceito em 22/12/2008.

\section{REFERÊNCIAS}

ASSOCIAÇÃO BRASILEIRA DE NORMAS TÉCNICAS - ABNT. NBR 6023: informação e documentação. Rio de Janeiro, 2002.

AMARAL, Marise Basso. A disciplina da natureza e a natureza das disciplinas: a ciência como produção cultural. Episteme, Porto Alegre, v. 2, n. 4, 1997.

BARRETO, Aldo de Albuquerque. Poucas notas para a elaboração de seu projeto, dissertação ou tese. PPGCI, ago. 2005.

BUFREM, Leilah Santiago. Linhas e tendências metodológicas na produção acadêmica discente do mestrado em Ciência da Informação do IBICT - UFRJ (1972-1995). 1996. Tese (Doutorado)- Departamento de Biblioteconomia, Setor de Ciências Humanas, Letras e Artes, Universidade Federal do Paraná, Curitiba, 1996. Concurso de Professor Titular de Métodos e Técnicas da Pesquisa.

LE COADIC, Yves-François. A ciência da informação. Brasília: Briquet de Lemos, 1996.

CAPES. Critérios de avaliação: comunicação/ciência da Informação: período de avaliação, 1998/2000. Disponível em: <http:// www.capes.gov.br>. Acesso em: 29 maio 2005.

$$
\text { período de avaliação, 2001/2003. }
$$

Disponivel em: <http://www.capes.gov.br>. Acesso em: 29 maio 2005.

Documento de área: comunicação/ciência da Informação: período de avaliação, 1998/2000. Disponível em <http:// www.capes.gov.br>. Acesso em: 29 maio 2005.

$$
\text { : período de avaliação, 2001/ }
$$

2003. Disponível em: 〈http://www.capes.gov.br>. Acesso em: 29 maio 2005 .

ECO-UFRJ;IBICT. Relação das dissertações defendidas. Rio de Janeiro, 2005. Disponivel em: <http://www.ibict.br/anexo-secoes/ teses.doutor.atual 2005. htm>. Acesso em: 18 maio 2005.

Relação das teses defendidas. Rio de Janeiro, 2005. Disponível em: <http://www.ibict.br/anexo-secoes/teses.doutor.atual2005.htm>. Acesso em: 18 maio 2005. 
Pesquisa disciplinar do corpus documental das teses de doutorado do PPGCI-IBICT/UFRJ: aplicando princípios e categorias para estudo interdisciplinar da ciência da informação no Brasil

FRANCO, Maria Laura Puglisi Barbosa. Análise de conteúdo. 2. ed. Brasília: Líber Livro, 2005.

GALVÃO, Maria Cristiane Barbosa. A ciência da informação: estudo epistemológico. 1997. Dissertação (Mestrado em Ciências)- Escola de Comunicações e Artes da Universidade de São Paulo, São Paulo, 1997.

GIL, Antonio Carlos. Como elaborar projetos de pesquisa. 4. ed. São Paulo: Atlas, 2002.

GOMES, Henriette Ferreira. Interdisciplinaridade e Ciência da Informação: de característica a critério delineador de seu núcleo principal. Data Grama Zero - Revista de Ciência da Informação, Brasília, v. 2, n. 4, ago. 2001. Disponível em: <http://www.dgz.org.br/ago01/ Art_04.htm>. Acesso em: 10 out. 2004.

IBICT. Departamento de Ensino e Pesquisa. Regimento do Programa de Pós-Graduação em Ciência da Informação: mestrado e doutorado, 2005. [S.1.: s.n.], 200-?.

JAPIASSU, Hilton. Interdisciplinaridade e patologia do saber. Rio de Janeiro: Imago, 1976
LENOIR, Yves. Didática e interdisciplinaridade: uma complementaridade necessária e incontornável. In: FAZENDA, Ivani C. A. (Org.). Didática e interdisciplinaridade. Campinas, SP: Papirus, 2005 .

MENDONÇA, Ercilia. Pesquisando sobre pesquisa: as configurações epistemológicas da Ciência da Informação nas teses de doutorado, convênio CNPq/IBICT-UFRJ/ECO. 2006. Dissertação (Mestrado em Ciência da Informação)- IBICT/UFF, Niterói, RJ, 2006.

OLIVEIRA, Marlene de. A investigação científica na Ciência da Informação: análise da pesquisa financiada pelo CNPq. 1998. Tese (Doutorado em Ciência da Informação)- Departamento de Ciência da Informação e Documentação da Universidade de Brasília, Brasília, 1998.

POMBO, Olga. Interdisciplinaridade: conceitos, problemas e perspectivas. Disponível em: 〈http://cfcul.fc.ul.pt〉. Acesso em: 06 abr. 2004.

Interdisciplinaridade e integração dos saberes. Disponível em: <http://cfcul.fc.ul.pt>. Acesso em: 06 abr. 2004.

TEIXEIRA, Olívio Alberto. Interdisciplinaridade: problemas e desafios. Revista Brasileira de Pós-Graduação, Sergipe, n. 1, jul. 2004. 